Eurostudia

\title{
Dunkle Technohöhlen in Berlin und anderswo
}

\section{Anton Marchel}

Volume 11, numéro 1, 2016

\section{Feuilleton}

URI : https://id.erudit.org/iderudit/1036322ar

DOI : https://doi.org/10.7202/1036322ar

Aller au sommaire du numéro

Éditeur(s)

Le Centre canadien d'études allemandes et européennes

ISSN

1718-8946 (numérique)

Découvrir la revue

Citer cet article

Marchel, A. (2016). Dunkle Technohöhlen in Berlin und anderswo. Eurostudia, 11(1), 81-82. https://doi.org/10.7202/1036322ar

Tous droits réservés ( Le Centre canadien d'études allemandes et européennes, 2016
Ce document est protégé par la loi sur le droit d'auteur. L'utilisation des services d’Érudit (y compris la reproduction) est assujettie à sa politique d'utilisation que vous pouvez consulter en ligne.

https://apropos.erudit.org/fr/usagers/politique-dutilisation/ 
Anton Marchel

Universität Leipzig

Es gibt in Berlin und anderswo eine Reihe von Clubs, die sich ganz der Technoszene verschrieben haben und deren Dresscode sich in der Farbvorgabe schwarz erschöpft. Eine alternative Farbwahl führt jedoch nicht zum Rauswurf, höchstens zu abschätzigen Blicken seitens des Szenekerns. Techno ist schließlich eine ernste Sache. Über diese Clubs wabern gewisperte Legenden durch die Städte. Auf leicht ironisierende Weise verarbeiten diese oft den Schmerz des Szeneausschlusses: Ich war zu fröhlich, deshalb wurde ich nicht reingelassen.

Man tanzt hier nicht in Gruppen, man kreischt auch nicht, wenn der „Bass-Drop“ kommt. Jeder tanzt konzentriert und seriös, versenkt sich in der Musik. Überall bewegen sich schwarze Gestalten durchs Dunkel des Clubs. Ein gewisser autonomer Schick gehört einfach dazu. Schwarz in schwarz verschmelzen sie mit der Nacht und keiner wiegt ein Gramm zu viel - die MDMA-Diät zeigt Wirkung.

Man geht in diesen Läden allerdings nicht einfach nur Feiern. Der hippe Mittelschichtsnachwuchs, der hier verkehrt, ist vielmehr in subversiver Mission unterwegs. Der Exzess ist die Vorwegnahme der befreiten Gesellschaft im Hier und Jetzt, praktischer Ausdruck der radikalen Gesellschaftskritik der Szenemitglieder. Es ist der lebendige Gegenentwurf zur verhassten Lohnarbeit und ihren disziplinarischen Implikationen. Sie sind der Widerstand in den westlichen Gesellschaften bzw. der Rest davon. Dieser hat sich immer mehr mit dem Wahnsinn vertäut. Die "beat generation“ hat die Rationalitätsgläubigkeit früherer Kader zerlegt. Die Hoffnung liegt jetzt in der Antiaufklärung.

Die Macht, die Angst vor diesen Leuten hat, versteht sie nicht. Sie ziehen sich modisch an, verfallen der Verwechslung verschiedener Wertformen mit dem Gebrauchswert, kaufen aus Spaß und schießen sich dann voll raus - sind so richtig kaputt. Die Haltung, die in diesem Verhalten zu 
Tage tritt, ist letztlich folgende: Grundsätzlich bewegen sie sich im Rahmen der FDGO und ab 30 werden sie auch so richtig hart arbeiten, aber bis dahin will man ordentlich Spaß haben. Und das Feiern in diesen Clubs scheint auch wirklich Spaß zu machen, auch wenn das aus der Außensicht nicht gleich ins Auge springt. Tellerförmige Pupillen schauen ins Leere. Der Klugscheißer aus dem Foucault-Seminar sieht inzwischen wie ein Gespenst aus. Hier und da bilden sich ketaminbasierte, autonome Kuschelgruppen. In den dunklen Ecken der Kellergewölbe fließen Gespräche und Stoff fliegt in die Nasen. Die Gespräche fangen an sich im Kreis zu drehen: „Wie viel hast du genommen?“, „Wann nehmen wir wieder was?". Und dann sind da noch die ganzen Wortspiele mit „ziehen“. Ziehrore gleiten über Handydisplays und liefern sich Wettrennen. Der Substanzenkonsum gerät zur Erweiterung der alltäglichen Leistungskonkurrenz. Distinktion mal anders: Wer sieht durchaus durch aus und wer ist am Kaputtesten?

Wenn die Etablierten der Mittelschicht nachts in diese Clubs gehen würden, würden sie in einen Abgrund schauen. Sie würden ihre umnebelten, halb-besinnungslosen Sprösslinge sehen und die Zukunft der eigenen Schicht, für deren Reproduktion sie alles getan haben, würde ihnen genauso dunkel erscheinen wie das Ambiente dieser Clubs. Doch wer dort bis zum Verlust der Muttersprache feiert, ist nur temporär außer Gefecht. Bald schon werden sie in einer Agentur mit flachen Hierarchien und Kicker arbeiten oder einfach die Kanzlei von Vati übernehmen. Und auch die Türme der Banken werden nicht leer bleiben müssen. Bei anderen ist das Denkvermögen auch während der Nacht noch nicht ganz verdampft. Und so kann man bei Zeiten beobachten, wie die „creative class“ im Wartestand nachdenklich auf Bänken sitzt und etwas in ihre ledergebundenen Notizbücher kritzelt. So wie sich Schiller vom Geruch fauler Äpfel inspirieren ließ, nutzen sie den Dunst aus Schweiß, Tabak, Bier und Erbrochenem als Katalysator einer der nüchternen Bevölkerung völlig unbekannten, intensiv gefühlten Kreativität.

Allerdings können die schönen Körpertempel der Szenemitglieder nicht ewig gegen die zersetzende, verpickelnde Wirkung des Amphetamins verteidigt werden. Zum Glück liegt das vom Verfassungsschutz errechnete durchschnittliche Ausstiegsalter aus der linksradikalen Szene bei 28 Jahren. 